\title{
Scanning setup for the investigation of fluorescence beam spectra
}

\author{
Łukasz Kłonowski, ${ }^{* 1}$ Elżbieta Bereś-Pawlik, ${ }^{1}$ Marek Rząca, ${ }^{2}$ and Roman Czarnecki ${ }^{2}$ \\ ${ }^{1}$ Institute of Telecommunications, Teleinformatics and Acoustics, Wroclaw University of Technology, \\ Wybrzeże Wyspiańskiego 27, 50-370 Wroclaw, Poland \\ ${ }^{2}$ Regional Specialistic Hospital, Oncology Department, Kamińskiego 73a, 51-124 Wroclaw, Poland
}

Received March 19, 2010; accepted March 28, 2010; published March 31, 2010

\begin{abstract}
In this paper we describe the scanning setup for investigating refracted beam spectra from changed cancer tissues. A special mechanical construction enables us to position measurement sensors using step motors and a micrometric XY stage. A fiber sensor which has been made of special fiber that does not provide any self fluorescence has been used for the illumination and detection.
\end{abstract}

Modern medicine has high hopes for precancerous diagnostics and therapy using the fluorescence phenomenon. Technological progress enables faster and more accurate detection of cancerous changes, which is very important for further treatment [1]. Investigations of tissue fluorescence allow us to determine whether the tissue is pathologically changed and also to define the infected area. This method enables diagnosis of diseased tissue without any surgical invasion. Detection is possible due to differences in fluorescence intensity of healthy and cancerous tissue (Fig. 1).

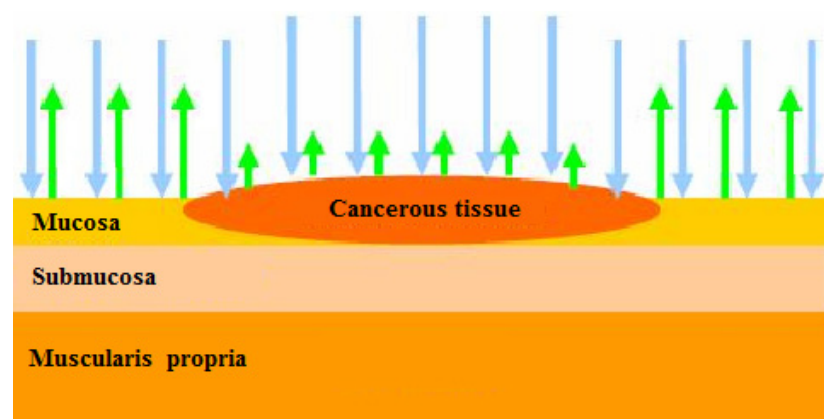

Fig. 1. Differences in fluorescence intensity in normal and cancerous tissue.

It is clearly lower in pathological areas then it is in healthy ones. This difference is due to the concentration of fluorophores, which is slight in cancer changed tissue when compared to normal tissue [2]. Lower intensity of observed fluorescence is also caused by differences in tissue structure. Carcinogenesis is a very rapid and uncontrolled process caused by mutation of the genetic

*E-mail: lukasz.klonowski@pwr.wroc.pl material of normal cells. This can lead to an outgrowth of cancer above the mother cells forming a tumor [3], [4].

The presented scanning setup (Fig. 2) was made for cancer changed tissue investigations with a point method. The sensor movement was provided in two directions. The micrometric XY stage is moved by two step motors controlled by computer software, which enables the definition of such parameters as distance, speed and direction of the movement. For fluorescence analysis, IOOBase32 software compatible with the Ocean Optics spectrophotometer was used. The base plate made of aluminum alloy provides the needed stability for the whole setup.

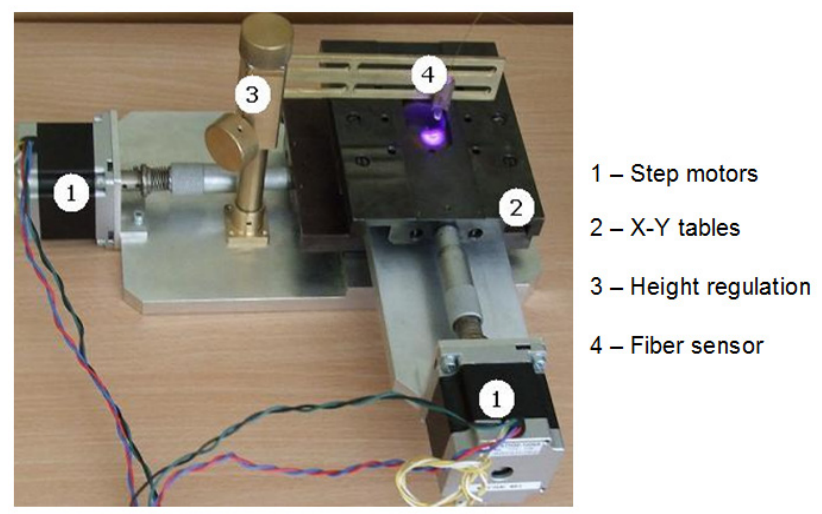

Fig. 2. Scanning setup.

The controlling software also enables 2D scanning of investigated tissue. It is a point by point scan with parameters verified by the user. Scanning speed depends on resolution and turning speed of step motors (minimal value for turning speed is $1 \mathrm{~ms}$ with $1,25 \mu \mathrm{m}$ scanning resolution). The sensor head is placed above the XY stage on the height regulation rod. A simple construction of the sensor's holding element allows heads of different diameters to be used. The fiber sensor was made of two lengths of fiber - illumination (Fig. 3d) and a detection arm (Fig. 3e). 


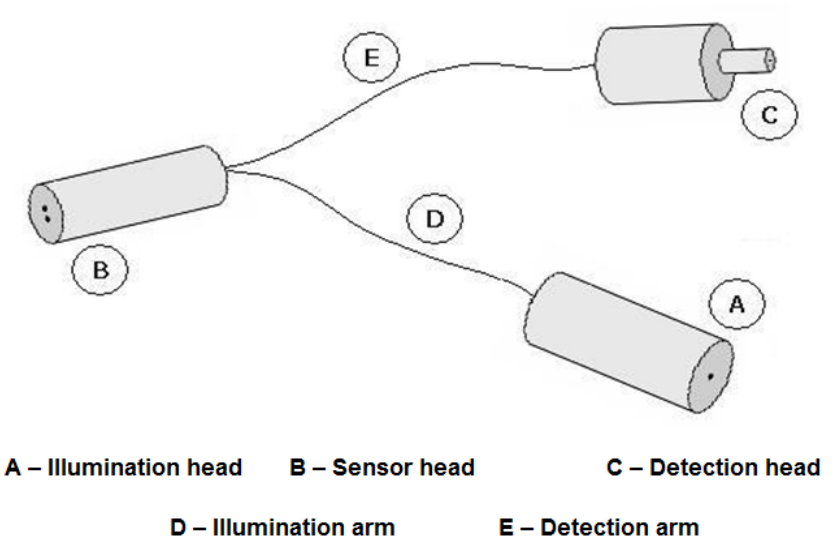

Fig. 3. Fiber sensor construction.

The illumination arm on one side is ended with an illumination head (Fig. 3a) to provide an easy connection with a laser source, on the other side - it is ended with a sensor head (Fig. 3b) to illuminate the investigated tissue. The detection arm in the sensor head is responsible for receiving tissue fluorescence. It is ended with a detection head (Fig. 3c), which is an SMA connector for easy coupling with a spectrophotometer.

The experiment setup (Fig. 4) contains a constructed scan device, a fiber sensor and an Ocean Optic's spectrophotometer (response in a few $\mathrm{ms}$ ). The illumination source was a GaN laser (404 nm) and the output power obtained at fluorescence excitation was $\sim 7,4 \mathrm{~mW}$.

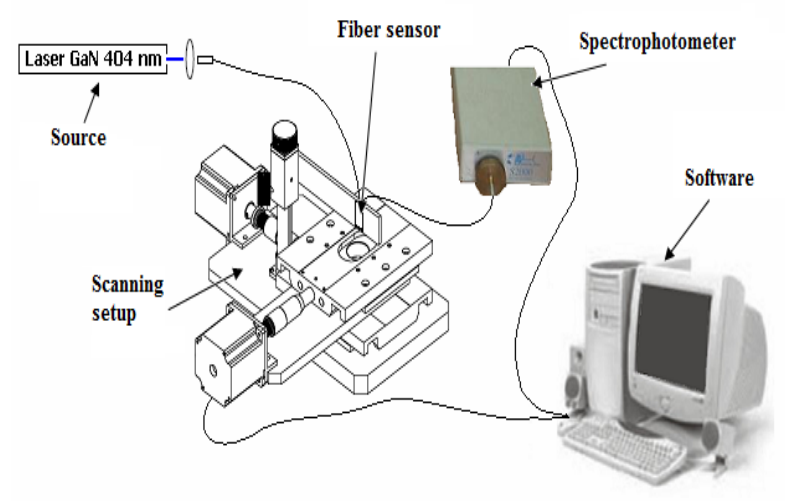

Fig. 4. Experiment setup.

We also placed a band-pass $(510 \pm 40 \mathrm{~nm})$ filter before the spectrophotometer to cut any parts of the source light. In Figure 5 we presented one of our point method results of a precancerous skin change investigation. Measurements were taken in 10 points along the blue line
(Fig. 5a). Low fluorescence intensity indicates advanced cancerous changes in almost all areas. The exception are the edges of tissue, which are the margin preventing reemission, and indicate higher intensity (measurement 10).
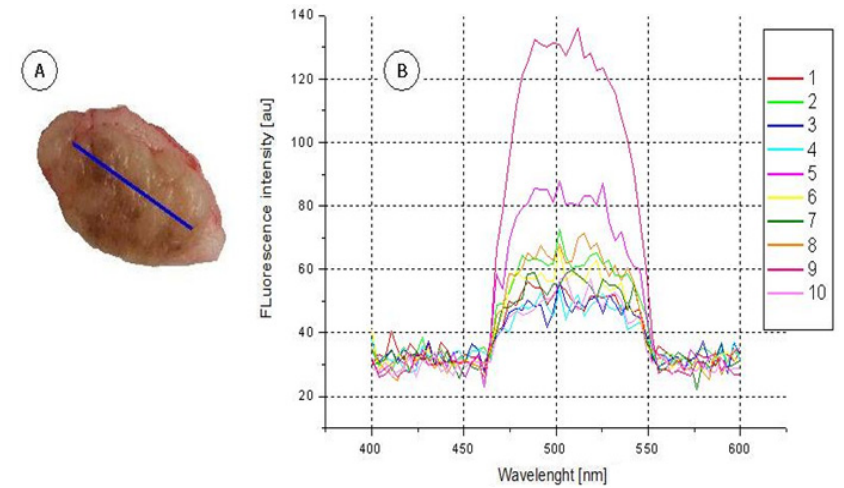

Fig. 5. Investigated tissue (A) and point measurement results (B).

The same tissue was scanned in 2D with an algorithm illustrated in Fig. 6a.
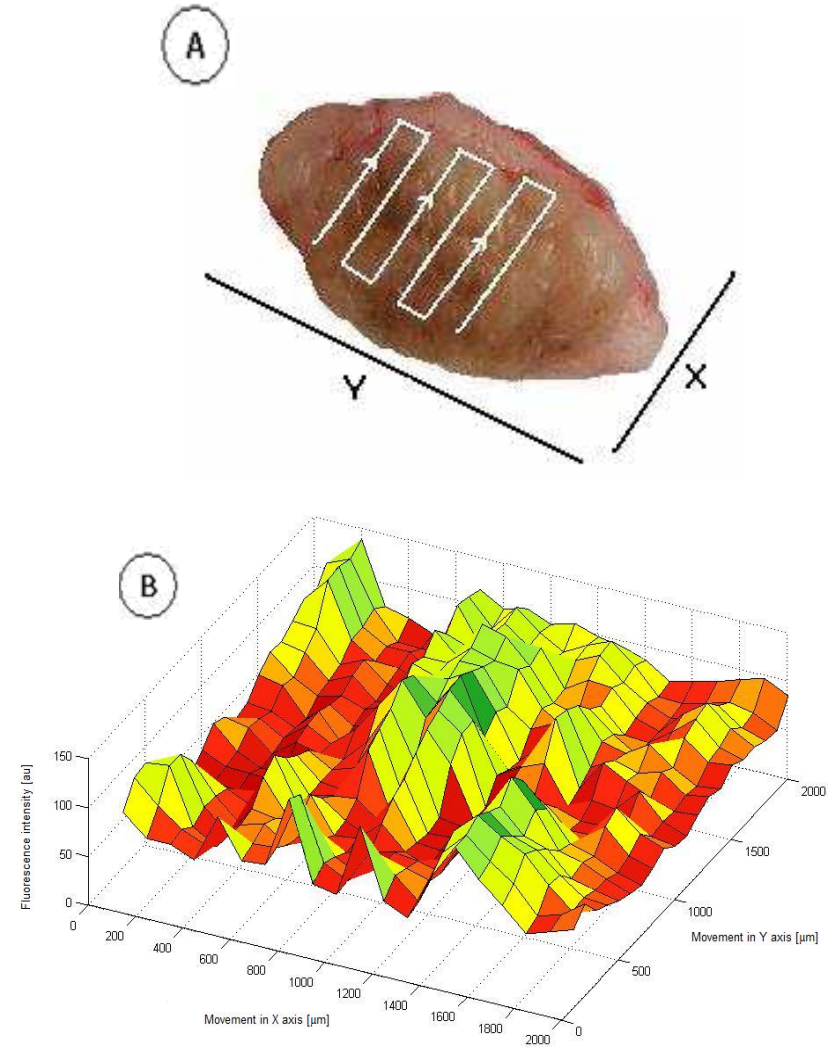

Fig. 6. 2D scanning algorithm (A) and spatial distribution of fluorescence intensity (B). 
The scan step was set at $300 \mu \mathrm{m}$ and we performed full tissue scanning. The obtained results (Fig. 6b) allow us to define pathological areas at various stages of disease advancement. The red areas indicate high cancerous changes and the orange or yellow areas show the spreading of the disease and lower levels of cancer advancement. This method can be very useful for determining how big the part of tissue should be cut during surgery and what should be the margin to avoid remission.

The presented scanning setup enables a researcher to separate a diseased area from healthy tissue and to define pathological areas of investigated tissue with great precision. The construction using step motors allows the sensor head above tissue to be positioned and slid with precision up to $1,25 \mu \mathrm{m}$ (because of construction of fiber sensor and used fiber we can obtain the size of the beam spot about $650 \mu \mathrm{m}$, which reduce the resolution). All scanning parameters are defined by the user from computer software. The experiment was made on human ex-vivo tissues in the Oncology Department of the Regional Specialist Hospital in Wroclaw.
The intensity of detected fluorescence lets the examiner determine the advancement of a disease. Two-dimensional distribution of fluorescence intensity allows separating cancer changed areas from healthy tissues, which can a be useful diagnostic tool.

\section{References}

[1] B. W. Chwirot, W. Jędrzejczyk, Luminescencja tkanek - nowe narzędzie wykrywania i lokalizacji nowotworów, Toruń (1995).

[2] J. A. Kiernan, M. Wessendorf, Autofluorescence:Causes and cures, Toronto Western Research Institute, http://www.uhnres.utoronto.ca/facilities/wcif/PDF/Autofluorescen ce.pdf

[3] B. Valeur, Molecular fluorescence - Principles and applications, Wiley - VCH, (2001).

[4] H. Zeng, A. McWillimas, S. Lam, Optical spectroscopy and imaging for early lung cancer detection, Photodiagnosis and Photodynamic Therapy 1, 111-122 (2004).

[5] W. Denk, J. Strickler, W. W. Webb, Two-Photon Laser Scanning fluorescence Microscopy, Science 248, 73-76 (1990).

[6] B. A. Flusberg, E. D. Cocker, W. Piyawattanametha, J. C. Jung, E. L. M. Cheung, M. J, Schnitzer, Fiber-optic fluorescence imaging, Nature Methods 2, 12 (2005).

[7] J. W. Lichtman, J. A. Conchello, Fluorescence microscopy, Nature Methods 2 (2005) 